\title{
RESEARCHPAPER
}

\section{Effect of vegetable and fruit waste on seed germination and growth of Solanum lycopersicum}

\author{
PRIYANKA MISHRA AND EAPEN P. KOSHY \\ Department of Molecular and Cellular Engineering, Jacob School of Biotechnology and Bio-Engineering, Sam \\ Higginbottom Institute of Agriculture, Technology and Sciences, ALLAHABAD (U.P.) INDIA \\ Email : eapen.koshy@shiats.edu.in
}

Article Info :Received : 01.12.2015; Revised : 03.01.2016; Accepted : 05.02.2016

The study was aimed to determine the effect of vegetable and fruit waste extract on seed germination and growth of Solanum lycopersicum. The domestic vegetable and fruit waste was used as both extract and decoction at different dilutions to analyze its effect on seed germination, leaf emergence, growth and plant biomass. Effect of different concentrations of waste extract and decoction was compared to that of distilled water (control). The results revealed that all the concentrations of extract/decoction promoted seed germination, also contributed to seedling height, plant growth and biomass accumulation. However, an increase in dilution ratios from 1:5 to 1:8 had a significant effect on germination and growth of tomato plants. This suggests that domestic waste, which is one of the major causes of environmental pollution, can be used as an alternative to synthetic plant growth nutrients.

Key words : Domestic waste, Seed germination, Tomato

How to cite this paper : Mishra, Priyanka and Koshy, P. Eapen (2016). Effect of vegetable and fruit waste on seed germination and growth of Solanum lycopersicum. Asian J. Bio. Sci., 11 (1) : 1-5 [Special Issue of AFBSAH-2016]. 